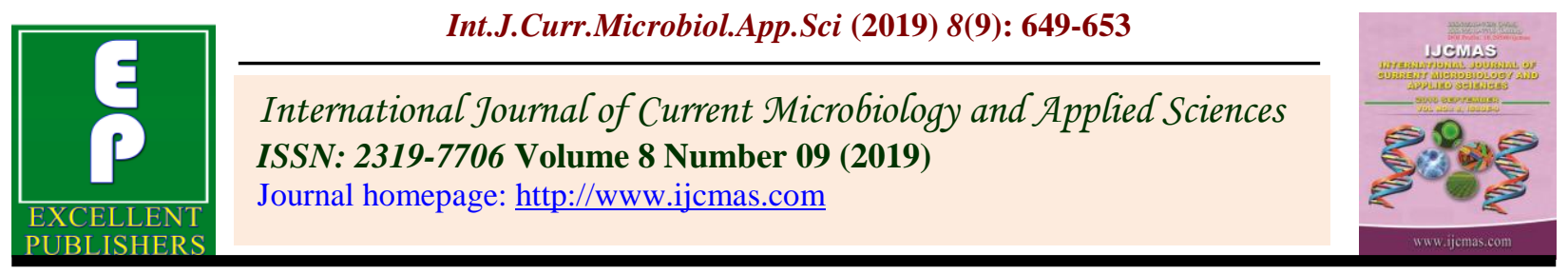

Case Study

https://doi.org/10.20546/ijcmas.2019.809.078

\title{
Traumatic Ventral Herniorrhaphy in a HF Cow - A Case Report
}

\author{
Vinod Kadapatti ${ }^{*}$, H.K. Santosh², K.M. Srinivasa Murthy ${ }^{2}$, S.P. Koushiek Yadav', \\ C.L. Sunil ${ }^{2}$, Tharasingh D. Lamani ${ }^{2}$ and B.N. Nagaraja ${ }^{2}$ \\ ${ }^{1}$ Department of AH and VS, Government of Karnataka, India \\ ${ }^{2}$ Department of Veterinary Surgery and Radiology, Veterinary College, KVAFSU, Hebbal, \\ Bangalore - 560 024, India \\ *Corresponding author
}

\section{A B S T R A C T}

\begin{tabular}{|l|}
\hline Ke y w o r d s \\
HF cow, Ventral \\
Hernia, \\
Herniorrhaphy \\
\hline Article Info \\
\hline $\begin{array}{l}\text { Accepted: } \\
\text { 04 August } 2019 \\
\text { Available Online: } \\
\text { 10 September } 2019\end{array}$ \\
\hline
\end{tabular}

\begin{abstract}
A recumbent $\mathrm{HF}$ cow aged 6.5 years weighing about $400 \mathrm{~kg}$ presented to the Veterinary College Hospital, Hebbal, Bangalore with a history of huge swelling in the right ventro-caudal lower flank region after falling on a peg 3 days back and it was recently parturited 15 days back. The animal was sedated with Xylazine hydrochloride and the area was desensitized by infiltrating $2 \%$ lignocaine hydrochloride. The hernial ring was closed by polyglactin 910 No.2 with simple interrupted suture pattern. Animal was recovered uneventfully and was discharged on $10^{\text {th }}$ post-operative day after removal of skin sutures.
\end{abstract}

\section{Introduction}

Hernia is a protrusion of the contents of a body cavity through a weak spot of the body wall. This may occur by accident or due to normal anatomical opening, which does not completely fulfill its physiological function. So a part of an internal organ bulges through a weakened muscle, tissue or membrane that would normally contain it. Hernias are caused by a combination of muscle weakness and strain (Sutradhar et al., 2009). Anatomically hernia consists of three parts, viz., (i) hernial ring, (ii) hernial sac and (iii) hernial contents (Amresh, 2009). In cattle's most common site of a hernia is the abdominal wall which consists of the muscles and ligaments, which acted as shield and the natural function of it is carrying the abdominal contents mainly the intestines. When any weakness extended in the abdominal wall, the shield loses its job and forms a hole called hernial ring, then part of the viscera of the abdominal cavity pass through the hole and then bulges; is visible on the skin as a hernia (Singh et al., 2014).

A primary diagnosis was made from the history and by palpation of the swollen region. Diagnosis of the cases, however, was confirmed by exploratory puncture of the swelling and demonstration of intestinal contents (Salim et al., 2015). There are several 
ways to surgical treatment of hernia which depends on the size of hernial ring at the site, as primary repair (herniorrhaphy) a surgical repair of simple hernia done with sutures placed in a straight line in the abdomen, surgical repair by using mesh (hernioplasty), of large and complex hernia by using networks and may be using a laparoscope (Demirkiran et al., 2003) and complex abdominal wall and hernia repair uses a combination of primary and mesh techniques (Whitfield-Cargile et al., 2011).

A ventral hernia occurs when part of the intestines protrude through the abdominal wall. Ventral hernia occurs generally as a result of external forces or trauma to the abdominal wall, automobile accident, weakening of the abdominal musculature or rupture of prepubic tendon. It is commonly seen along the costal arch, high or low in the flank, between the last few ribs or in the ventral abdominal wall near the mid line (Singh et al., 2014). One of the clearest sign is the prominent swelling under the skin and the contents of the ventral hernia remain in the abdomen toward the gravity or stretch the pleural cavity if the diaphragm is integrated and in this case the external swelling may not be clear. The contents of the hernia is not adequate with the size of the measurement ring has drooped a large part of the intestine through a small opening of the abdominal wall or may be an opening in the abdominal wall, while the highest content travel beneath the abdominal skin, the diagnosis of the hernia makes through the contents of the hernia and hernial ring be clear or palpated the viscera under the skin, but the diagnosis of irreducible hernias defaulted and needed to use the X-ray to reflect the lack of abdominal wall continuity and sometimes the loss of a strip of the abdominal wall or change the natural place of the organ (Lund et al.,2004 and Abdin-bey and Ramadan, 2001). Unilateral ventral hernias in large animals commonly in ruminants on the right side of the abdominal floor occur infrequently in advanced pregnancy in cow, sheep and goats, these hernias are usually due to trauma, the increase weight of the gravid uterus and fetus and possibly other change, weaken the abdominal floor, characterized by a unilateral ventral sagging of the abdominal floor. Calving may be difficult because of the inability of the abdominal muscles to contract equally and strongly and force the fetus through the birth canal (Roberts, 2004).

\section{Case history and clinical observations}

A recumbent HF cow aged 6.5 years weighing about $400 \mathrm{~kg}$ presented to the Veterinary College Hospital, Hebbal, Bangalore with a history of huge swelling in the right ventrocaudal lower flank region after falling on a peg 3 days back and it was recently parturited 15 days back. There was no evidence of external injury. On clinical examination of the swelling, huge voluminous soft mass was felt along with location of large ring at the dorsal aspect of the mass closer to the distal portion of $12^{\text {th }}$ rib, suggestive of ventral hernia. As the formations of adhesions were absent, the contents were reducible in nature (Fig. 1 and 2).

\section{Treatment and Discussion}

As the condition of the animal was critical in nature, immediate hernial repair was planned on the next day. Animal was withheld water for 12 hours and feed for 24 hours (Sagar et al., 2010). Animal was casted in left lateral recumbency in such a way that the complete exposure of the hernial sac could be accessible easily. However, Hendrickson and Suzanne (2005) and Sarker et al., 2012 controlled the animal in dorsal oblique recumbency in case of external hernia like ventral and umbilical, after sedation or tranquilization. Detection of hernial ring with the index finger also aided 
diagnosis. Either the reducibility of content after placed animal in dorsal recumbency or the contents were pushed back into the abdomen. In case of reducible hernia, the contents went back to the abdominal cavity and the hernial ring became evident (Salim, et al., 2015). Inj. Xylazine hydrochloride @ 0.1 $\mathrm{mg} / \mathrm{kg}$ BW was administered intramuscularly to calm down the animal. Then the hernial ring was located and the area around the ring was prepared for aseptic surgery. It was desensitized by injecting $60 \mathrm{ml}$ of inj. 2\% lignocaine hydrochloride in a ring manner. In case to make a herniorrhaphy, xylazine hydrochloride can be used as a better sedative while $0.5 \%$ bupivacaine hydrochloride can be used as a local analgesic for longer duration of action (Hendrickson and Suzanne 2005; Sarker et al., 2012). Whereas, Sagar et al., (2010) reported that the animal was premedicated with Triflupromazine hydrochloride @ $0.05 \quad \mathrm{mg} / \mathrm{kg} \quad \mathrm{BW}$ intramuscularly followed by local infiltration at the site using $2 \%$ lignocaine. Then given a linear oblique incision over the ring, separated the skin and subcutaneous tissue by blunt dissection to reach the hernial sac. After opening the sac, $15-20 \mathrm{~cm}$ hernial ring was located, made it adhesion free by breaking them. The hernial contents found was large intestinal loops, were extended in the subcutaneous space between the lateral aspect of right quarter of the udder and skin. After placing the intestinal loops inside the abdominal cavity, the ring was closed by using polyglactin 910 No. 2 in a simple interrupted suture pattern. Whereas Rafid et al., (2017) closed the hernial ring by overlapping sutures using chromic catgut No. 3 or 4 with umbilical tape in case of large ring. The abdominal muscles were apposed by chromic catgut No. 2 in a simple interrupted suture pattern. Finally the skin edges were apposed by nonabsorbable synthetic polyamide No.1 in horizontal mattress suture pattern. The animal was administered broad spectrum antibiotic inj. strepto-penicillin @ $10 \mathrm{mg} / \mathrm{kg}$ BW intramuscularly once daily for 7 days, antiinflammatory inj. meloxicam @ $0.3 \mathrm{mg} / \mathrm{kg}$ BW intramuscularly once daily for 5 days. Wound dressing was carried out on alternative day. The animal was recovered uneventfully; it was discharged on $10^{\text {th }}$ post-operative day by removal of the skin suture and instructing the owner that the animal should be fed on soft food for about 2 weeks after the operation to minimize pressure on the site of incision (Amresh, 2009) (Fig. 3-5).

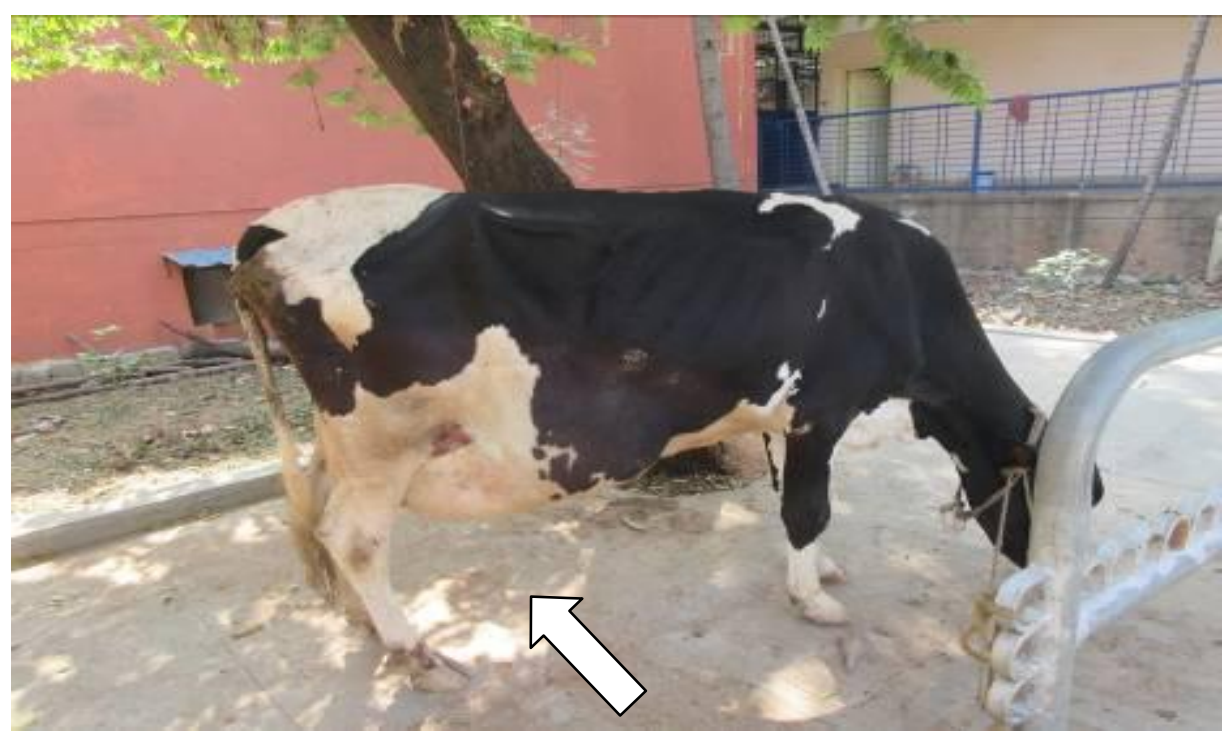

Fig.1 Figure is showing ventral hernia (white arrow) 


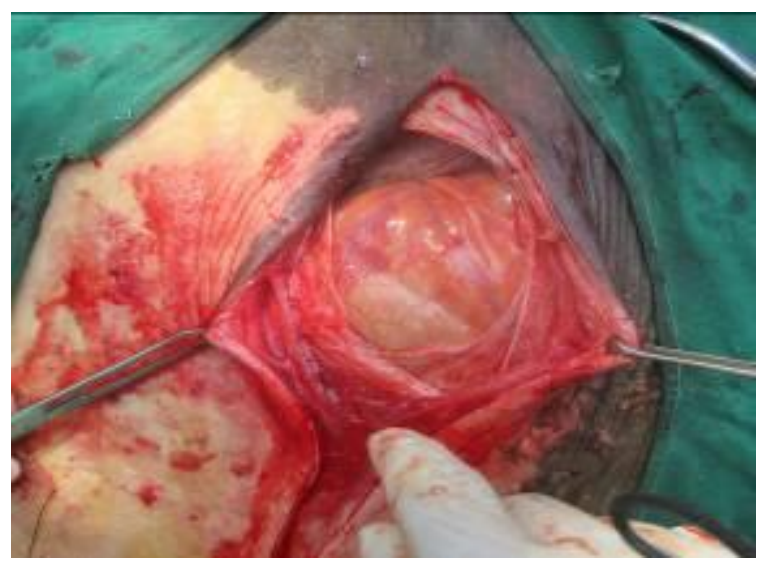

Fig.2 Exposure of hernial sac

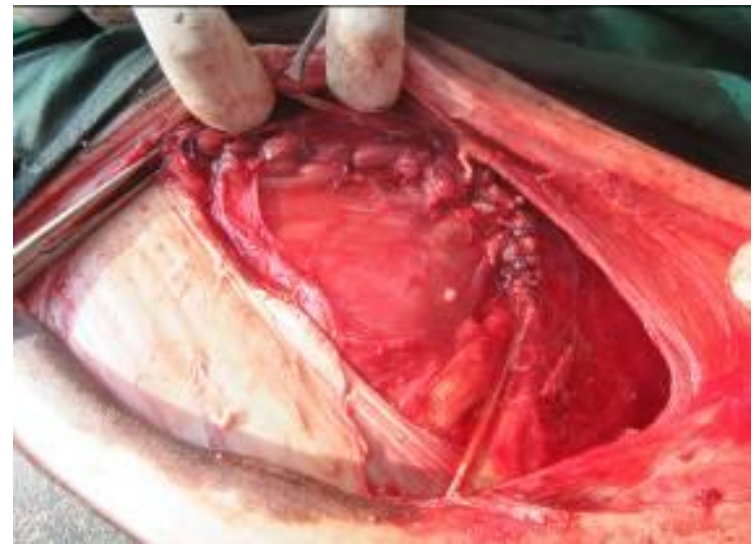

Fig.4 Complete closure of the hernial ring

\section{References}

Abdin-bey, M.R., and Ramadan, R.O. 2001. Retrospective study of hernias in goats. Scient. J. King Faisal. Univ, 2(1): 7788.

Amresh , K., 2009. Surgery of Abdomen and Organs of Digestive System. In: Veterinary Surgical Technique, Ch.14, pp 310- 312.

Demirkiran, A.E., Ozgun, H, Balkaya, M, Cevikel, H, Culhaci, N and Gurel, M. 2003. Strangulated ventral hernia model in rats, J. Investigative Surg, 16(2): 9397.

Hendrickson, D.A., and Suzanne E.T. 2005. Large Animal Inguinal Hernia Repair .In Veterinary Laparoscopic Surgery, Ch.7, pp 237-240.

Lund. E.P., Bergenfeldt, M and Burcharth, F.

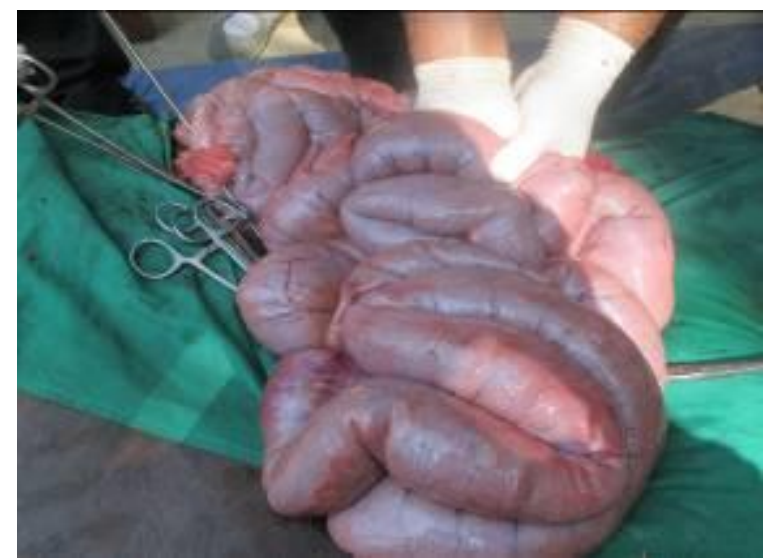

Fig.3 Hernial contents (large intestinal loops)

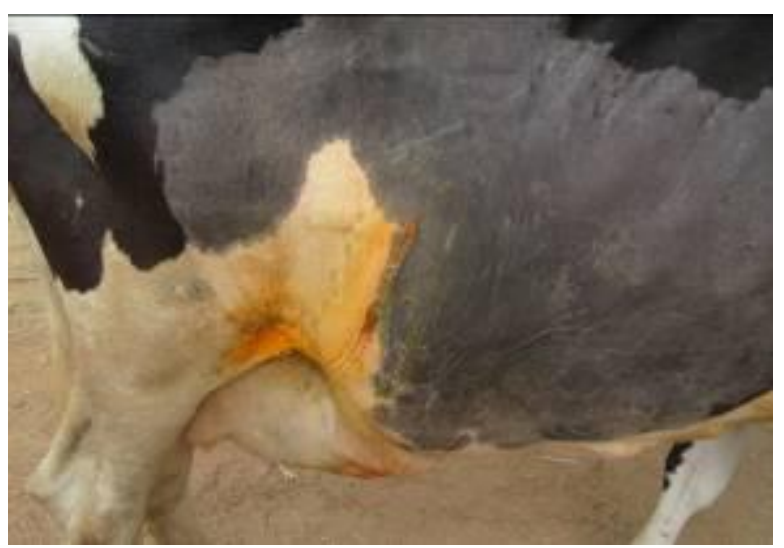

Fig.5 Complete healed wound

2004. Traumatic abdominal hernia caused by cough, presenting with intestinal obstruction, Hernia, 8(4): 399401.

Rafid, H.F., Al-Husseiny, S.H and Al-Ameer, A.N.A., 2017. Surgical treatment of hernia in cattle: A review. QJVMS, 17(2): 61-68.

Roberts, S.J., 2004. Disease and Accident of the Gestation Period. In: Veterinary Obstetrics and Genital Disease (Theriogenology). Ch. 7, pp 184 -185.

Sagar, P.V., Harish, D and Babu, P.P., 2010. Ventral hernia in an Ongole cow: A case Report, Vet. World, 3(2): 90-91.

Salim, M.D., Abul Hashim, M, Juyena, N.S, Arafat, Y.A, Dey, R.K, Bag, A and Islam, M.S. 2015. Prevalence of Hernia and Evaluation of Herniorrhaphy in Calves, Int. J. Nat. Soc. Sci, 2(4): 35-43. 
Sarker, N.C., Hashim, M.A and Ray, B.P. 2012. Effect of Sedative Techniques on Physiological Parameters of Calves at (Minor Surgical Procedures) or Herniorrhaphy, J. Agric. Sci, 7(2): 6675.

Singh, B.A., Preethi, K.O, Devi, A.K, Gangwar, N.K, Katiyar, S.S, Kale, G, Patel, H and Singh, N. 2014.Ventral Abdominal Hernioplasty Using Nylon Mesh In A Cow, Indian Vet. J, 91(11): 93-94.
Sutradhar, B.C., Hossain, M.F, Das, B.C, Kim,G and Hossain, M. A. 2009. Comparison Between Open And Closed Methods Of Hernioraphy In Calves Affected With Umbilical Hernia, J. Vet. Sci, 10(4): 343-347.

Whitfield-Cargile, C.M., Rakestraw, P.C, Hardy, J.N, Cohen, D and Davis, B.E. 2011. Comparison of Primary Closure of Incisional Hernias in Horses With and Without the Use of Prosthetic Mesh Support, Equine Vet. J, 43(39): 69-75.

\section{How to cite this article:}

Vinod Kadapatti, H.K. Santosh, K.M. Srinivasa Murthy, S.P. Koushiek Yadav, C.L. Sunil, Tharasingh D. Lamani and Nagaraja, B.N. 2019. Traumatic Ventral Herniorrhaphy in a HF Cow - A Case Report. Int.J.Curr.Microbiol.App.Sci. 8(09): 649-653. doi: https://doi.org/10.20546/ijcmas.2019.809.078 